\title{
Mongolian Spots as a Clue to Mucopolysaccharidoses
}

\author{
Parmar PN ${ }^{1}$, Kalathiya MB², Rathod VB ${ }^{3}$ \\ ${ }^{1}$ Dr. Parin Niranjanbhai Parmar, MBBS, MD, Assistant Professor, ${ }^{2}$ Dr. Mitul B. Kalathiya, MBBS, MD, Assistant Professor, \\ ${ }^{3}$ Dr. Vipul B. Rathod, MBBS, MD Resident. All from KT Children Hospital, PDU Medical College, Rajkot, India.
}

$\mathrm{M}^{\mathrm{s}}$ ongolian spots are irregular blue patches of skin pigmentation. Most commonly they are seen over the sacral area and buttocks, however, rest of the trunk and extremities may also be affected. They usually disappear by 6 months of age.
It is generally said that Mongolian spots have no clinical significance. However, it is a less known fact that unusually excessive Mongolian spots, especially at unusual sites as well as their unusual persistence (beyond 6 months of age) may be a clue to mucopolysaccharidoses, especially Hurler's and Hunter's syndrome.

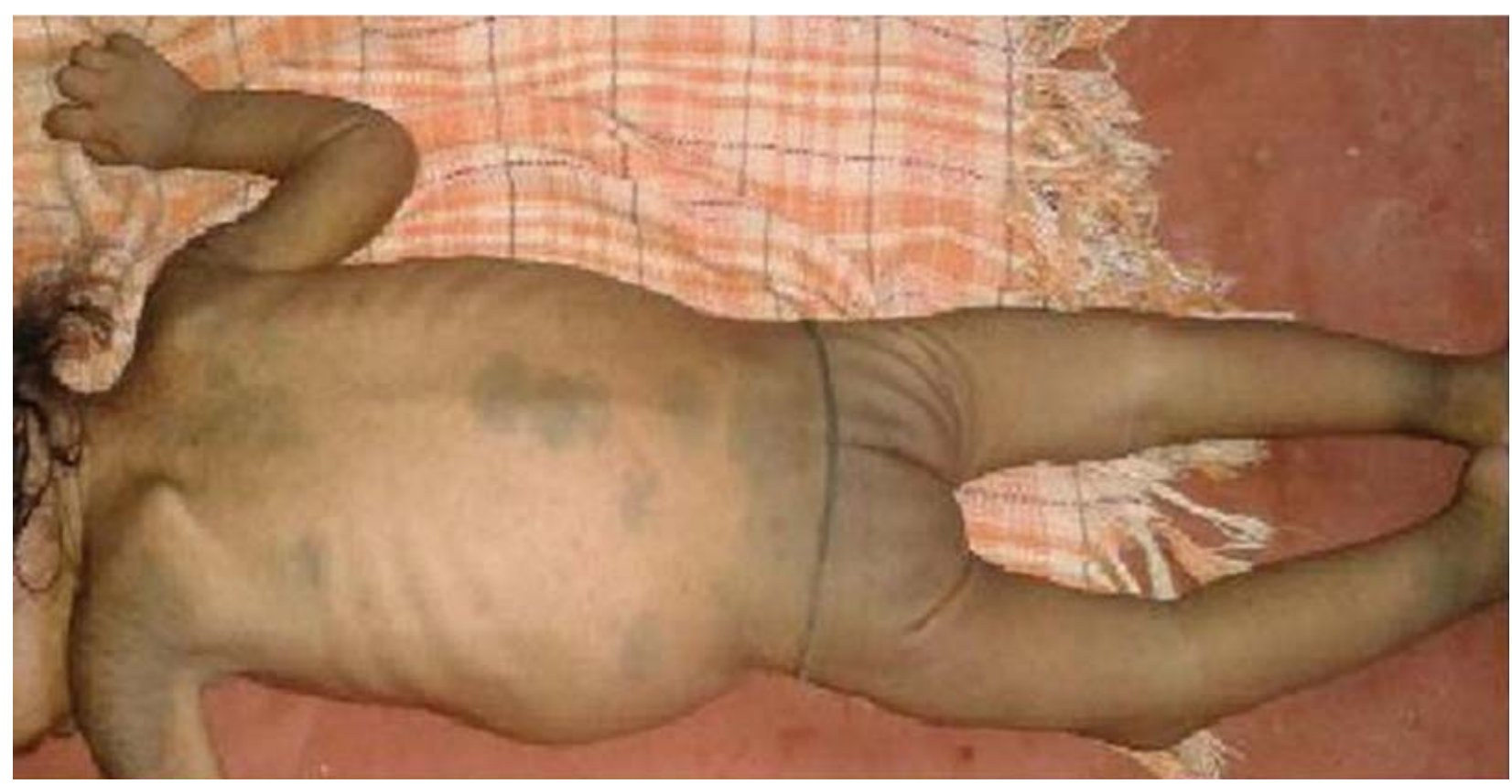

The photo shows excessive Mongolian spots in a 1 year old female, who was diagnosed to be a Hurler's syndrome.

\section{Dr. Parin N. Parmar}

“Niraj”, 1 /4, Jyotinagar; Kalawad Road;

Rajkot-360005, India.

E-mail: parinparmar13@yahoo.co.in

\section{How to cite this article ?}

Parmar PN, Kalathiya MB, Rathod VB. Mongolian Spots as a Clue to Mucopolysaccharidoses. J Nepal Paediatr Soc 2013;33(1):83. 